\title{
Stent fracture after endovascular treatment patient with subclavian vein thrombosis: difficult diagnosis and complication of venous thoracic outlet syndrome
}

\author{
Pawel Wierzchowski, Pawel Brazis, Arkadiusz Migdalski, Arkadiusz Jawień \\ Department of Vascular Surgery and Angiology, Nicolaus Copernicus University in Toruń, \\ Collegium Medicum in Bydgoszcz, Poland
}

\begin{abstract}
Subclavian vein thrombosis is relatively rare. It constitutes 4 to $10 \%$ of all cases of venous thrombosis and is often associated with compression or cannulation of the subclavian vein. We present the case of a patient with Paget-Schroetter syndrome treated in our center for right subclavian vein thrombosis as a result of the venous thoracic outlet syndrome (VTOS). In the case described below, VTOS was unrecognized and the stent fracture following endovascular treatment led to a relapse of venous thrombosis. Secondary angioplasty and stenting with subclavian vein decompression was successfully made. The patient was regularly monitored throughout the following year and there was no relapse of clinical symptoms. Conclusions: in case of subclavian vein thrombosis, decompression is a very important step in the management of VTOS. It prevents recurrence of thrombosis and potential complications.
\end{abstract}

Key words: stent fracture, subclavian vein thrombosis, venous thoracic outlet syndrome, Paget Schroetter syndrome

Acta Angiol 2020; 26, I: 40-44

\section{Introduction}

Subclavian vein thrombosis is relatively rare. It constitutes 4 to $10 \%$ of all cases of venous thrombosis $[1,2]$. Most often, it is secondarily associated with central vein cannulation, hypercoagulation and cancers. In $20 \%$ of cases, is idiopathic and it is impossible to clearly indicate its cause. In these cases, thrombosis is often associated with compression of the subclavian vein and is a clinical manifestation of the venous thoracic outlet syndrome (VTOS).

In patients with VTOS, the subclavian vein (SCV) is compressed between the clavicle, the first rib, anterior scalene muscle, costoclavicular ligament, and subclavicular muscle. Chronic compression leads to fibrosis of the wall and narrowing of the vessel lumen. Slowed and turbulent flow results in thrombus formation which then leads to the clinical manifestation of venous thrombosis.
Medical imaging of thrombosis located in this region includes ultrasound, computed tomography angiography $(\mathrm{aCT})$, and magnetic resonance angiography (aMRI). Modern endovascular techniques allow restoring blood flow as soon as a few weeks from the onset of symptoms. Treatment of venous thrombosis inflicted by compression syndrome should include decompression surgery.

We present the case of a patient with Paget-Schroetter syndrome treated in our center for right subclavian vein thrombosis as a result of the venous thoracic outlet syndrome (VTOS). In the case described below, VTOS was unrecognized and the stent fracture following endovascular treatment led to a relapse of venous thrombosis.

This 42-year-old female patient, an architect by occupation, was referred to our facility in May and June 2015 due to pain and oedema of the right upper

Address for correspondence: Pawel Wierzchowski, Department of Vascular Surgery and Angiology, Nicolaus Copernicus University in Torun, Collegium Medicum in Bydgoszcz, Poland, Sklodowskiej 9, 85-094 Bydgoszcz, Poland, e-mail: pawel.wierzchowski@gmail.com 


\begin{tabular}{|c|c|c|c|c|}
\hline May-June 2015 & June 2015 & 23 June 2015 & June-November & November, \\
\hline $\begin{array}{l}\text { - Emergency unit: } \\
\text { cancer susp. }\end{array}$ & $\begin{array}{l}\text { - Oncological unit: } \\
\text { diagnostics and } \\
\text { cancer exclusion }\end{array}$ & $\begin{array}{l}\text { - Vascular surgery } \\
\text { department } \\
\text { diagnostics and } \\
\text { treatment of SCF } \\
\text { thrombosis (PTA } \\
\text { and stenting) }\end{array}$ & $\begin{array}{l}\text { - 1-th follow-up: } \\
\text { no restenosis } \\
\text {-2-nd follow-up: } \\
\text { restenosis and } \\
\text { stent fracture }\end{array}$ & $\begin{array}{l}\text { - Resection of the } \\
\text { first rib with } \\
\text { secondary } \\
\text { angioplasty and } \\
\text { re-stenting }\end{array}$ \\
\hline
\end{tabular}

Figure I. Diagnostics and treatment of patients with subclavian vein thrombosis

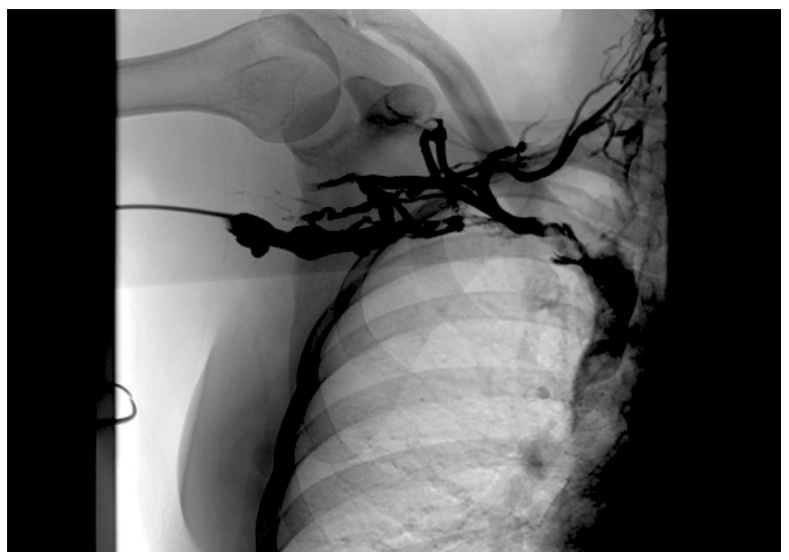

Figure 2. Preliminary phlebography

limb. Figure I presents the patient's history of visits and hospitalizations. Comorbidities included Hashimoto's thyroiditis and degenerative lesions in the cervical spine. The patient had a family history of breast cancer (both mother and sister). The first symptoms started at the beginning of May 20I5. Between May and June 2015 , the patient was seen several times in the Hospital Emergency Unit and underwent diagnostics in the Oncology Center. The family history of cancer and the cervical spondylotic radiculopathy suspicion skewed the diagnosis. Two ultrasound examinations during Emergency Unit visits did not reveal SCV (subclavian vein) thrombosis, which was finally established during the follow-up consultation on June 23, 2015. Subclavian vein thrombosis was diagnosed approximately two months after the onset of first symptoms. The computed tomography confirmed diagnosis of proximal subclavian vein thrombosis but no signs of compression and anatomical malformations such as additional cervical rib were detected.

The patient was qualified for phlebography. Occlusion of SCV was confirmed (Fig. 2) and angioplasty of the subclavian vein was performed with stenting (Wallstent Uni $10 \times 68 \mathrm{~mm}$, Boston Scientific) (Fig. 3). Control

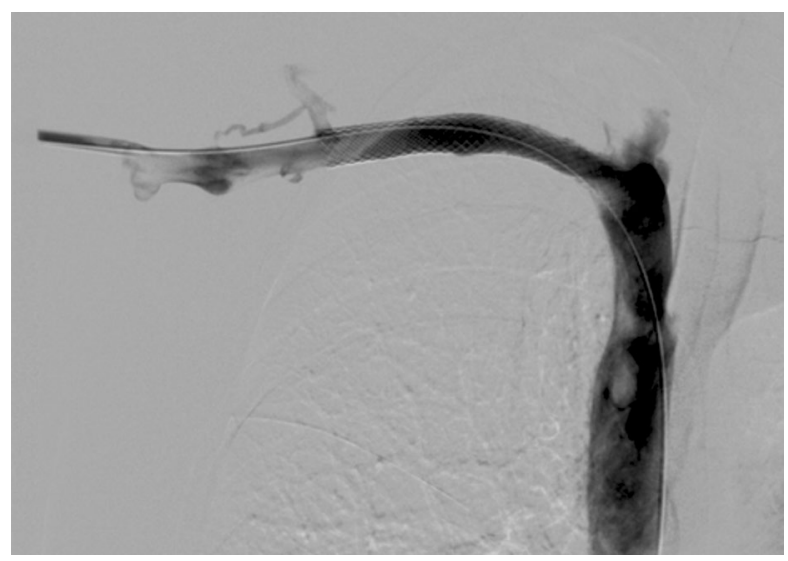

Figure 3. Final phlebography of the subclavian vein after angioplasty and stent placement

phlebography showed correct flow in the stent and absence of collaterals. No compression and narrowing of the stent were detected between the first rib and clavicle during dynamic phlebography with adducted and elevated limb. Therefore, no further surgery was required at this stage.

After the procedure, limb edema and pain decreased and the patient was discharged the next day. Between July and November 2015, the patient was seen in the outpatient clinic. The first follow-up visit did not reveal any signs of SVC thrombosis recurrence. Approximately three months after discharge, a follow-up CT scan was performed which revealed signs of narrowing and stent fracture (Fig. 4). Recurrence of clinical symptoms was also observed at that time. The VTOS with recurrent stent thrombosis was diagnosed and the patient was qualified for open surgery. The first rib (Fig. 5) was resected through supraclavicular and infraclavicular access sites.

In the second stage, re-angioplasty with second stent implantation was performed (Wallstent Uni 10 $\times 42 \mathrm{~mm}$, Boston Scientific) (Fig. 6). The patient was regularly monitored throughout the following year and there was no relapse of clinical symptoms. A follow-up 


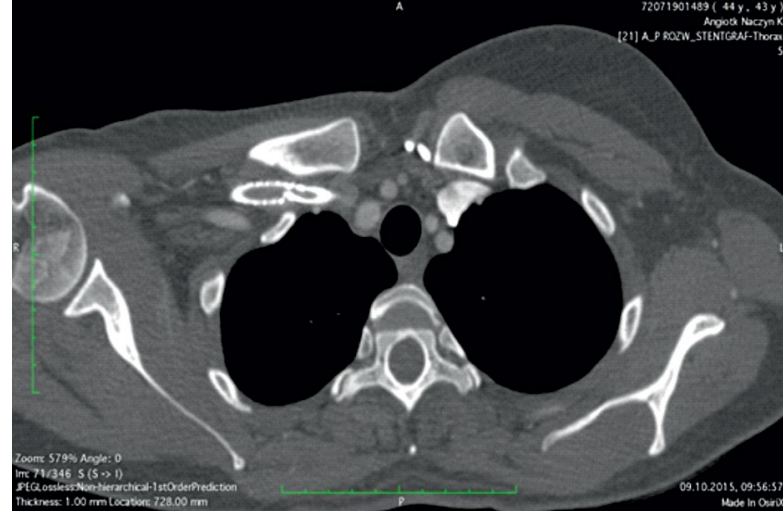

Figure 4. Stent fracture in SCV

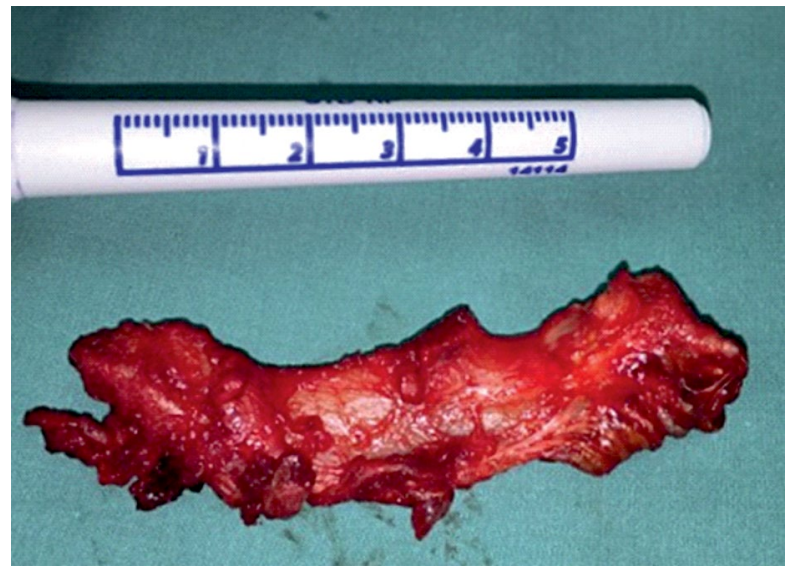

Figure 5. The first rib was removed

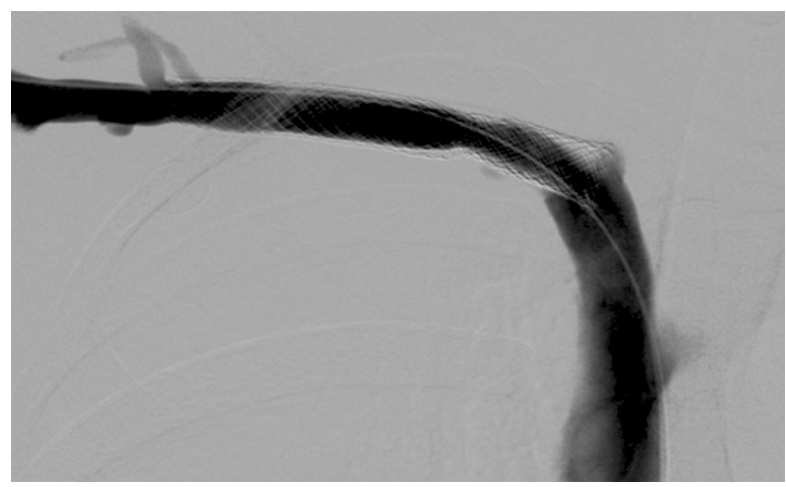

Figure 6. Re-stenting of SCV

CT scan revealed a stenosis of approximately $40 \%$ in the stent fracture site.

\section{Discussion}

Subclavian vein thrombosis due to thoracic outlet syndrome, also known as the Paget-Schroetter syn-

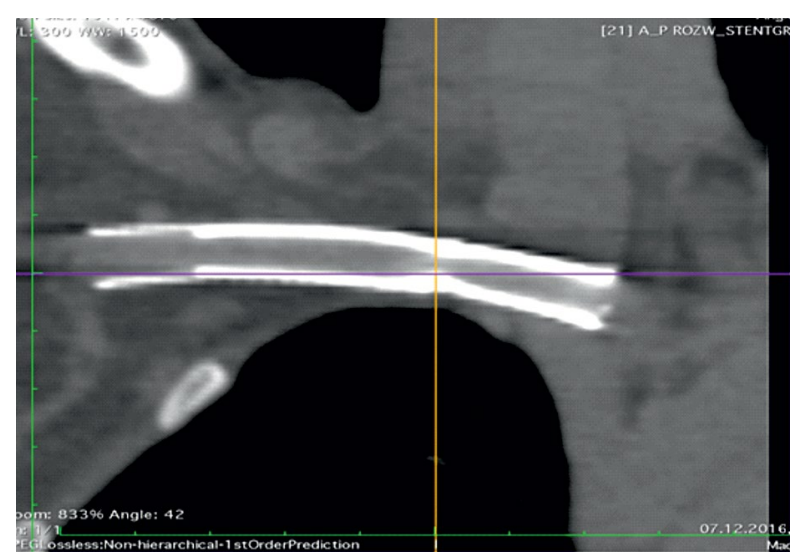

Figure 7. CT follow-up after 12 months

drome, mostly affects young, healthy, active people. The case of the 42-year-old female patient presented in this paper reveals not only diagnostic difficulties and complications such as stent fracture but also the risk of recurrence of subclavian vein thrombosis. The time between the onset and diagnosis was long and reached nearly two months.

The ultrasound performed at that time did not reveal any signs of SVC thrombosis. Although the ultrasound is specifically tailored to detect vein thrombosis, the acoustic echo-shadow of the clavicle makes the assessment difficult. It is easier to diagnose SCV thrombosis when the thrombus extends through the subclavian and axillary veins [3]. In the described case, the distal parts of the subclavian vein and axillary and brachial veins were not affected (Fig. 2).

The CT scan and MR imaging are more precise methods that allow detection of VTOS as well as thrombosis. These types of examinations should be conducted with the limb abducted and elevated above the head [3, 4].

According to some authors, phlebography is the most effective diagnostic method, particularly useful in patients with recurrent symptoms within six weeks after the previous episode [4]. In this case, after onemonth follow-up, Adson's maneuver was negative and no other signs of stent compression were detected. No further treatment or additional invasive diagnostic methods were required.

Causal treatment is a very important step in the management of VTOS. It prevents recurrence of thrombosis and potential complications. Decompression of the neurovascular bundle improves the function of the limb, as does thrombolysis. There are different opinions regarding the sequence of procedures [5]. In most cases of SCV thrombosis in the course of VTOS, it is recommended to start with catheter-directed thrombolysis 
(CDT) and vessel decompression as a second stage. This recommendation concerns mostly patients with primary thrombosis when the onset occurred up to two weeks before treatment [6]. In these cases, a CDT with r-tPA and pharmacomechanical thrombectomy are usually very effective. Such treatment may be completed with balloon angioplasty. Stenting, however, is not recommended in cases when decompression surgery was not performed due to the high risk of stent damage and early recurrence of thrombosis [7].

Urschel et al. compared the results of treatment in 22 patients with primary SCV and primary stenting with 384 patients treated surgically after initial thrombolytic therapy. All patients with stents required re-intervention due to recurrent thrombosis within six weeks after implantation. By contrast, no cases of thrombosis have been reported in patients treated with thrombolysis and VTOS decompression [8].

The decompression surgery was not performed initially in the case described here due to no apparent anatomical malformations, such as a cervical rib. Since there was a long delay between the first symptoms and treatment ( $>6$ weeks), thrombolysis was not indicated as well. Therefore, primary angioplasty was performed and, due to residual stenosis, the self-expandable stent was implanted. The vascular and clinical results following endovascular treatment were very good. Intraoperative radiological images did not reveal stent compression. Clinical symptoms relieved within a few days. Despite the initial good outcomes, stent fracture and re-thrombosis that required surgical treatment occurred within the first few months.

In the case of VTOS, decompression surgery is recommended directly after revascularization or no later than one month after thrombolytic treatment. Patients with a higher risk of thrombosis recurrence, such as in residual stenosis, require more urgent surgery [9].

There are three operational access sites: axillar, supraclavicular, and infraclavicular. The axillary access site allows good visualization of the costo-clavicular region and resection of the first rib [10]; however, in the case of thrombosis resulting from VTOS, simultaneous phlebography and angioplasty should be performed. The paraclavicular access site additionally allows reconstruction of the subclavian vein with a venous patch or venous graft [1I, 12]. Some authors recommend only the subclavian access site, possibly followed by balloon angioplasty. This procedure provides sufficiently good intraoperative insight into the costo-clavicular space while minimizing the risk of damaging the phrenic nerve $[13,14]$. In the patient discussed in this article, paraclavicular access was used in order to obtain a good long-term result.
Anticoagulant therapy is another important aspect of treating patients with subclavian vein thrombosis. This type of therapy should be applied for several months after initial treatment with low molecular weight heparin. The question of if and when such treatment should be terminated remains open. Following the elimination of the initial factor of thrombosis, anticoagulants can be discontinued after three months. Patients with recurrent thrombosis require chronic administration of anticoagulants [15], which is the treatment that was implemented in this case.

\section{Conclusions}

In our opinion decompression is a very important stage of VTOS treatment and should be done before or immediately after endovascular treatment. Diagnostics of subclavian vein thrombosis requires aCT scans, aMRI, and dynamic phlebography, especially in unclear and recurrent cases. Removal of the first rib seems to be the most effective decompression procedure in VTOS.

\section{Conflict of interest}

None.

\section{References:}

I. Bernardi E, Pesavento R, Prandoni P. Upper extremity deep venous thrombosis. Semin Thromb Hemost. 2006; 32(7): 729-736, doi: 10.1055/s-2006-95/458, indexed in Pubmed: I7024601.

2. Lee JA, Zierler BK, Zierler RE. The risk factors and clinical outcomes of upper extremity deep vein thrombosis. Vasc Endovascular Surg. 2012; 46(2): 139-144, doi: | 0. I | 77/ | 5385744 | | 432 | 45, indexed in Pubmed: 22328450.

3. Melby SJ, Vedantham S, Narra VR, et al. Comprehensive surgical management of the competitive athlete with effort thrombosis of the subclavian vein (Paget-Schroetter syndrome). J Vasc Surg. 2008; 47(4): 809-820; discussion 821, doi: 10.1016/j. jvs.2007.10.057, indexed in Pubmed: 18280096.

4. Vemuri C, Salehi P, Benarroch-Gampel J, et al. Diagnosis and treatment of effort-induced thrombosis of the axillary subclavian vein due to venous thoracic outlet syndrome. J Vasc Surg Venous Lymphat Disord. 2016; 4(4): 485-500, doi: 10.1016/j. jvsv.2016.01.004, indexed in Pubmed: 27639006.

5. Ryan C, Mouawad N, Vaccaro P, et al. RRI7. First Rib Resection Effectively Treats Venous Thoracic Outlet Syndrome With or Without Preoperative Thrombolysis and Also Improves Symptoms in Cases of Venous Congestion Without Deep Venous Thrombosis. J Vasc Surg. 2015; 61(6), doi: 10.1016/j. jvs.20I5.04.372.

6. Schneider DB, Curry TK, Eichler CM, et al. Percutaneous mechanical thrombectomy for the management of venous thoracic outlet syndrome. J Endovasc Ther. 2003; 10(2): 336-340, doi: 10.1 I77/15266028030 1000226, indexed in Pubmed: 12877619. 
7. Rutherford RB. Primary subclavian-axillary vein thrombosis: the relative roles of thrombolysis, percutaneous angioplasty, stents, and surgery. Semin Vasc Surg. 1998(I I): 91 -95.

8. Urschel H, Patel A. Paget-Schroetter syndrome therapy: failure of intravenous stents. The Annals of Thoracic Surgery. 2003; 75(6): 1693-1696, doi: 10.1016/s0003-4975(03)00116-4.

9. Angle N, Gelabert HA, Farooq MM, et al. Safety and efficacy of early surgical decompression of the thoracic outlet for $\mathrm{Pa}$ get-Schroetter syndrome. Ann Vasc Surg. 200I; 15(I): 37-42, doi: 10.1007/s 1001600100I7, indexed in Pubmed: II221942.

10. Machleder HI. Evaluation of a new treatment strategy for Paget-Schroetter syndrome: spontaneous thrombosis of the axillary-subclavian vein. J Vasc Surg. 1993; 17(2): 305-315; discussion 316, doi: 10.1016/0741-5214(93)90416-j, indexed in Pubmed: 8433426.

II. Vemuri C, Thompson R. VS5. Operative management of venous thoracic outlet syndrome. J Vasc Surg . 2015; 6I(6), doi: I0.1016/j.jvs.2015.04.214
12. Thompson RW, Schneider PA, Nelken NA, et al. Circumferential venolysis and paraclavicular thoracic outlet decompression for "effort thrombosis" of the subclavian vein. J Vasc Surg. 1992; 16(5): 723-732, doi: 10.1067/mva. 1992.41523, indexed in Pubmed: 1433660 .

13. Molina JE, Hunter DW, Dietz CA. Protocols for Paget-Schroetter syndrome and late treatment of chronic subclavian vein obstruction. Ann Thorac Surg. 2009; 87(2): 416-422, doi: 10.1016/j. athoracsur.2008.11.056, indexed in Pubmed: 19161749.

14. Siracuse Jj, Johnston PC, Jones DW, et al. Infraclavicular first rib resection for the treatment of acute venous thoracic outlet syndrome. J Vasc Surg Venous Lymphat Disord. 20 I5; 3(4): 397-400, doi: 10.1016/j.jvsv.2015.06.002, indexed in Pubmed: 26992617.

15. Tomkowski W, Kuca P, Urbanek T, et al. Venous thromboembolism - recommendations on the prevention, diagnostic approach and management. The 2017 Polish Consensus Statement. Acta Angiologica. 2017; 23(2): 35-7I, doi: 10.5603/ aa.2017.0008. 